\title{
Feminismos, mulheres e esportes: questões epistemológicas sobre o fazer historiográfico
}

Silvana Vilodre Goellner

\begin{abstract}
Resumo: Este texto analisa a contribuição das epistemologias feministas e dos estudos de gênero para as pesquisas historiográficas sobre mulheres e esportes. Para tanto, analisa a emergência do campo denominado de "História das Mulheres", bem como a utilização da categoria "gênero" como uma ferramenta analítica que possibilita compreender os processos históricos através dos quais se deu a inserção, permanência e ampliação da participação das mulheres no campo das práticas corporais e esportivas. Enfatiza, ainda, as teorizações do feminismo póscrítico visto que, ao romperem com a categoria universal "mulher" têm visibilizado as diferenciações e pluralidades presentes nos modos das mulheres existirem e de viverem suas feminilidades.
\end{abstract}

Palavras-chave: Feminismo. Mulheres. Esportes. História.

\section{INTRODUÇÃO}

A "escolha" de uma prática de pesquisa, dentre outras, diz respeito ao modo como fomos e estamos subjetivadas/os, como entramos no jogo de saberes e como nos relacionamos com o poder. Por isto, não escolhemos, de um arsenal de métodos, aquele que melhor nos atende, mas somos "escolhidas/os" (e esta expressão tem, na maioria das vezes, um sabor amargo) pelo que foi historicamente possível de ser enunciado; que para nós adquiriu sentidos; e que também nos significou, nos subjetivou, nos (as)sujeitou. (CORAZZA, 2002, p. 124)

Adotar como objeto de investigação as mulheres, os esportes e suas historicidades é, sem dúvida alguma, uma opção individual e está permeada por significações que cada autor/a empreende ao seu esforço investigativo. É ainda político porque circunscrito ao ambiente acadêmico, onde temáticas como essas se encontram,

\footnotetext{
* Doutora em Educação. Professora Adjunta da Escola de Educação Física da UFRGS.
} Apoio CNPq. E-mail: goellner@terra.com.br 
muitas vezes, nas zonas de sombra, sendo responsabilidade do/a pesquisador/a trazê-las à luz, conquistar espaços, atribuir-lhes sentidos. Político também porque pesquisar implica fazer opções epistemológicas e metodológicas e estas nunca são neutras, a-históricas, muito menos universalistas.

Pesquisar histórias de mulheres no âmbito do esporte e da educação física tem se constituído como uma possibilidade investigativa de várias autoras e autores no Brasil. ${ }^{1}$ A despeito das diferentes correntes epistemológicas e metodológicas que utilizam para analisar essa presença, cabe mencionar que estes textos possibilitam tornarem-se visíveis trajetórias particulares que, de uma maneira ou outra, construíram e constroem a história do esporte nacional. Permitem conhecer diferentes mulheres cujos corpos ememórias chegam até nosso presente através de rastros do passado, vestígios recolhidos de um outro tempo e ressignificados à luz da interpretação do presente.

Em que pesem as diferentes abordagens privilegiadas nestas pesquisas, vale lembrar que, como qualquer outro campo de conhecimento, a História é historicamente datada, está ancorada no tempo e tem narrado o mundo de acordo com interesses pessoais, políticos, sociais, econômicos, culturais e étnicos, evidenciando, sobretudo, a impossibilidade de descrever o real tal como ele é. Isso significa afirmar que a História é um dos muitos discursos que existem acerca do mundo e da humanidade cujas narrativas tanto podem fazer lembrar o que deve ser lembrado quanto invisibilizar o que deve ser esquecido. Segundo Michel de Certeau (1982, p. 66) “[...] toda a pesquisa historiográfica se articula com um lugar de produção sócio-econômico, político e cultural e está submetido a imposições, ligada a privilégios, enraizada em uma particularidade".

Pensando no que comumente tem sido denominado de "História das Mulheres", é possível vislumbrar um horizonte pleno, de multiplicidades, de interpretações, de olhares, de formas de narrar suas trajetórias, histórias de vida, biografias, ações políticas, ${ }^{1}$ Essa afirmação pode ser observada no número crescente de trabalhos apresentados, por
exemplo, no CBCE, que desde 1979, acontece a cada dois anos sob organização do Colégio
Brasileiro de Ciências do Esporte. Pode ser reconhecida, ainda, nos Anais dos Encontros de
História da Educação Física e Esporte cuja primeira edição aconteceu em 1997 na UNICAMP
e a última (10 $10^{\text {a }}$ edição), em 2006, na Universidade Federal do Paraná.

Movimento, Porto Alegre, v.13, n. 02, p.171-196, maio/agosto de 2007. 
culturais, esportivas, entre outras. Essa multiplicidade advém tanto das configurações teóricas e metodológicas adotadas pelas/os historiadoras/es, quanto das questões afetas à compreensão que se tem acerca do objeto específico de investigação, ou seja, sobre as próprias mulheres. Ou seja, no campo específico da historiografia sobre mulheres, tanto se pode encontrar abordagens que tratam das mulheres como um bloco uníssono quanto aquelas que as analisam ressaltando suas particularidades e diferenças. ${ }^{2}$

Nessa perspectiva, torna-se pertinente ressaltar a importância dos atravessamentos disciplinares visto que a História, ao dialogar com a literatura, com os estudos de gênero e com as epistemologias feministas, tem permitido a emergência de diferentes práticas discursivas conferindo visibilidade às mulheres como sujeitos históricos. Razão pela qual não há como falar de uma "História das Mulheres", mas de "histórias" e de "mulheres", onde inexiste uma hegemonização do fazer historiográfico visto que as mulheres são plurais e que as abordagens possíveis de narrá-las podem ser absolutamente diversas. ${ }^{3}$

Identificada, por vezes, como parte do que se poderia dizer de uma historiografia dos excluídos, o campo acadêmico "História das Mulheres" buscou se diferenciar da historiografia oficial que, de certa maneira, ao abordar a História dos homens como da espécie e não do gênero, acabou por cunhar a memória da humanidade e sua História a partir do masculino. ${ }^{4}$ Invisibilizado acadêmica e politicamente,

\footnotetext{
${ }^{2}$ Essas duas compreensões podem ser identificadas em estudos historiográficos (internacionais e nacionais) que tematizam as mulheres no esporte. Tem sido também, objeto de reflexões de autoras/es que discutem gênero e esporte tendo como aporte teórico as epistemologias feministas. Discussões como estas podem ser identificadas em Pfister e Hartmann-Tews (2003); Silva, Gomes, Graça e Queirós (2005); Goelner (2005); Devide (2005); King e MacDonald (2007); entre outros.

${ }^{3}$ Sobre esse tema, ler História das Mulheres, de Joan Scott (1992), em que a autora faz uma análise sobre a estruturação desse campo de estudos ressaltando seu caráter político e epistemológico.

${ }^{4}$ Segundo Humm (1989), algumas historiadoras feministas cunharam uma nomenclatura particular, dentro do campo dos Women Studies: o termo herstory que, inicialmente, foi utilizado para chamar a atenção para o uso universal do masculino genérico subtendido na history (his-story). A motivação para esta crítica fundamenta-se no desajustamento entre a linguagem e a realidade a que esta se refere o que acaba por omitir o papel desempenhado pelas mulheres como sujeitos sociais na História. Ao propor a utilização do termo herstory pretendem conferir às mulheres um lugar na História e, ao mesmo tempo, devolver a história às mulheres na medida em que este termo refere-se a teorização e o registro da experiência, da vida e da linguagem das mulheres (MACEDO e AMARAL, 2005).
}

Movimento, Porto Alegre, v.13, n. 02, p.171-196, maio/agosto de 2007. 
o fazer das mulheres foi narrado a partir da idéia de um sujeito genérico universal representado, nas sociedades ocidentais, como sendo o homem, branco, heterossexual e cristão.

Marcar a diferença talvez tenha sido o primeiro grande passo da historiografia feminista que, ancorada em diferentes aportes epistemológicos, políticos e metodológicos, construiu uma narrativa tão diversa quanto necessária. ${ }^{5}$ Ainda que tenham sido várias as abordagens adotadas pelas feministas para estruturar o campo acadêmico "História das Mulheres", merece destaque o ensaio publicado, em 1986, pela historiadora norte-americana Joan Scott, intitulado "Gender: a useful category of historical analysis". ${ }^{6}$ Considerado como um clássico dos estudos de gênero, este texto trouxe significativa contribuição ao campo da historiografia contemporânea ao enfatizar a necessidade de se analisar o caráter relacional existente entre os sexos. Para Scott:

[...] não se pode conceber mulheres, exceto se elas forem definidas em relação aos homens, nem homens, exceto se eles forem diferenciados das mulheres. Além disso, uma vez que o gênero foi definido relativa aos contextos social e cultural, foi possível pensar em termos de diferentes sistemas de gênero e nas relações daqueles com outras categorias como raça, classe ou etnia, assim como em levar em conta a mudança (SCOTT, 1992, p. 87).

Destaca-se, aqui, o uso do termo "gênero" como uma categoria de análise cuja utilização possibilitou que novas abordagens emergissem dentro dos estudos sobre mulheres, pois, ao enfocarem o caráter relacional entre os sexos, enfatizavam "[...] as conotações sociais do gênero em contraste com as conotações físicas do sexo" (SCOTT, 1992, p. 81).

\footnotetext{
${ }^{5} \mathrm{O}$ movimento feminista não pode ser entendido como um bloco homogêneo. Desde suas origens apresentou uma série de nuances e dissonâncias e o próprio termo feminismo não é unívoco. Autoras como Janet R. Richards (1994) e Judith Evans (1995) analisaram e classificaram diferentes grupos e vertentes. Richards identifica duas grandes vertentes: 0 feminismo liberal e o radical. Evans identifica uma rede mais ampla de orientação com realce para as vertentes liberais, radicais, culturais, socialistas e pós-modernas. Sobre esse tema ler Dicionário da Crítica Feminista, organizado por Ana Macedo e Ana Luisa Amaral (2005). 6 Uma tradução do texto foi publicada pela Revista Educação \& Realidade no ano de 1990 a partir de uma versão francesa. Em 1995, o mesmo periódico veicula nova versão traduzida do texto original em inglês.
}

Movimento, Porto Alegre, v.13, n. 02, p.171-196, maio/agosto de 2007. 
Embora seja consensual a recusa à idéia de que o sexo anatômico é determinante na imposição das diferenças entre homens e mulheres, é necessário considerar que o termo "gênero" também não é observado de forma homogênea. ${ }^{7}$ Num primeiro momento, esteve relacionado aos estudos das mulheres, mais especificamente àqueles estudos que advinham de uma militância feminista dos anos 60 e 70 do século XX e que trazia como uma das suas intenções denunciar a situação de dominação da mulher em relação ao homem. No campo historiográfico, abordagens como estas revelavam a quase invisibilidade das mulheres como sujeitos, seja nas grandes narrativas sobre a História da humanidade, seja como protagonistas na própria produção historiográfica. Essa invisibilidade motivou as historiadoras feministas a reivindicar à História a tarefa de salientar a importância da participação das mulheres na constituição das sociedades e culturas, reconhecê-las no espaço público e político e nos meandros do cotidiano. Esse movimento produz e é também produzido pela própria crise paradigmática da historiografia contemporânea, ${ }^{8}$ em que as abordagens tradicionais da escrita da história, cuja objetividade se propunha a narrar os grandes feitos, fatos políticos e trajetórias heróicas passam a ser substituídos por outros fazeres historiográficos que possibilitaram o surgimento de novos objetos, problemas, instrumentos analíticos e fontes (LE GOFF, 1994). Despontam, a partir dessa crise, temas como História dos negros, dos operários, das mulheres, do

\footnotetext{
${ }^{7}$ Segundo Nicholson (2000), embora a palavra gênero tenha um significado bastante claro para o feminismo, na verdade, ela é usada de duas maneiras diferentes e, até certo ponto contraditórias. De um lado, o "gênero" é sempre usado em oposição a "sexo" para descrever o que é socialmente construído em oposição ao que é biologicamente dado. Essa compreensão é mais visível nas primeiras teorizações feministas. De outro, tem sido cada vez mais usado como referência a qualquer construção social que tenha a ver com a distinção masculino/ feminino, incluindo as construções que separam corpos femininos de corpos masculinos. Aqui há a percepção "de que a sociedade forma não apenas a personalidade e o comportamento, mas também as maneiras como o corpo aparece" (p. 9). Sobre esse tema ler, também, Stolke (2004), Macedo e Amaral (2005) e Mariano (2005).

8 Podemos, talvez, situar os sintomas da mudança nos anos 1970 ou mesmo um pouco antes, com a crise de maio de 68 , com a Guerra do Vietnã, a ascensão do feminismo, o surgimento da New Left, em termos de cultura... Foi quando então se insinuou a hoje comentada crise dos paradigmas explicativos da realidade, ocasionando certas rupturas epistemológicas profundas que puderam em xeque os marcos conceituais dominantes na História" (PESAVENTO, 2003, p. 8).
}

Movimento, Porto Alegre, v.13, n. 02, p.171-196, maio/agosto de 2007. 
cotidiano, das coisas, das instituições... objetos de investigação até então marginalizados pela Historiografia tradicional. ${ }^{9}$

"História das Mulheres" passa a se configurar como um campo de produção acadêmica e sua consolidação se dá, entre outros motivos, pela articulação que faz com outros campos temáticos, tais como os estudos sobre gênero, sexualidade e, sobretudo, com os aportes epistemológicos feministas. Essa ressalva dever ser mencionada visto ser o movimento feminista, desde a sua origem, aquele que mais reclamou às mulheres a sua condição de sujeito reivindicando a desnaturalização das essências do humano. No dizer de Tânia Swain:

\begin{abstract}
Os feminismos têm sido, assim, ponta de lança para a crítica da ciência, das verdades instituídas, dos valores transformados em leis, apontando para a historicidade absoluta do humano e dos sentidos criados em práticas discursivas, marcadas de tempo e de espaço e por elas universalizadas. Fala-se inclusive de "o feminismo", ignorando a pluralidade e a riqueza das análises produzidas em milhares de textos, marcando a produção do conhecimento no feminino da mesma essência única que se atribui às mulheres. De fato "o homem" designa o universal, o humano, "os homens", as suas divisões individuais; a "mulher" aponta para uma espécie do humano, o "outro", e "as mulheres" apenas o quantitativo. (SWAIN, 2004)
\end{abstract}

Ainda que muitas reivindicações feministas possam ser semelhantes, há que referenciar a impossibilidade de falar de feminismo no singular porque são múltiplas as suas vertentes e estas operam com conceitos e representações, por vezes, similares, por vezes contraditórias, inclusive no campo historiográfico. ${ }^{10}$ Nesse particular, mais do que entender as especificidades teóricas, conceituais e analíticas das diferentes e possíveis abordagens no que tange às histórias das mulheres me parece ser necessário registrar neste

\footnotetext{
${ }^{10}$ Sobre esse tema ler História \& Gênero de Andréa Lisly Gonçalves (2006).

${ }^{9}$ Traduzido e publicado no Brasil em 1988, o livro Os excluídos da história: operários, mulheres e prisioneiros, de autoria de Michelle Perrot, é exemplar dessa afirmação. No que respeita à História das Mulheres, vale destacar duas publicações organizadas sobre essa temática: a coletânea de cinco livros publicada no início dos anos 90 , na França, sob direção de Michelle Perrot e Georges Duby, intitulada História das Mulheres e o livro História das Mulheres no Brasil, organizado por Mary Del Priori e Carla Bassanezzi (1997).
}

Movimento, Porto Alegre, v.13, n. 02, p.171-196, maio/agosto de 2007. 
texto o deslocamento do foco investigativo do termo "mulher" para "mulheres". Aqui não é apenas uma mudança gramatical que está a acontecer, mas uma mudança de cunho epistemológico em que (mulher), dotada de uma essência única e "verdadeira", desdobra-se em mulheres, seres localizados em suas especificidades e experiências múltiplas (SWAIN, 2004).

É exatamente a universalização da categoria "mulher" um dos pontos a inaugurar um outro olhar sobre o gênero oriundo da produção do feminismo pós-estruturalista. Esta abordagem encontra fundamentação nas teorizações de Michel Foucault e Jacques Derrida, quando privilegiam a centralidade da linguagem como um local de produção das relações que a cultura estabelece entre corpo, sujeito, conhecimento e poder. Para essa perspectiva teórica, o conceito de gênero engloba, também, as formas de construção social, cultural e lingüística que estão implicadas nos processos de diferenciação entre mulheres e homens, levando em consideração, portanto, que as instituições, as leis, as políticas, as normas, enfim, os processos simbólicos de cada cultura, ao mesmo tempo em que são constituídas por representações de masculinidade e feminilidade, produzem essas representações ou, ainda, as ressignificam (MEYER, 2000).

A vertente pós-estruralista, ao operar com o conceito de gênero, projeta para o termo uma configuração que está para além da sua recorrência como uma categoria analítica. O gênero é observado como algo que integra a identidade do sujeito, que faz parte da pessoa e a constitui. Decorre dessa representação uma importante diferenciação com relação a outras abordagens feministas e historiográficas, que ao analisarem as mulheres e suas historicidades, recorrem a conceitos como os de estereótipo e/ou papéis sexuais. Papéis e estereótipos revelam-se como estruturas fixas baseadas em padrões ou regras estabelecidas por cada sociedade. Assim, os sujeitos aprendem a ser homens e mulheres adaptando-se ou aprendendo a comportar-se de acordo com esses papéis. Nesse caso, ficariam sem exame não apenas as múltiplas formas que podem assumir as masculinidades e feminilidades, como também as complexas redes de poder que (através das instituições, dos discursos, dos códigos, das práticas, dos símbolos, etc.) constituem hierarquias entre os gêneros (LOURO, 1997, p. 24).

Movimento, Porto Alegre, v.13, n. 02, p.171-196, maio/agosto de 2007. 
Enfim, para os estudos decorrentes do pós-estruturalismo, masculinidade e feminilidade se definem reciprocamente visto não existir nenhuma essência a priori determinada para uma e outra identidade. Essas identidades, ao contrário, são produzidas na cultura não havendo uma fixidez na sua produção. Rejeitam, por conseguinte, a idéia da existência de uma essência que está colocada para um e outro sexo uma vez que não se está a considerar a construção cultural dos gêneros, mas a enfatizar um caráter já fixado da condição humana.

Nas palavras de Dagmar Meyer:

\begin{abstract}
Como construção social do sexo, gênero foi (e continua sendo) usado, então, por algumas estudiosas, como um conceito que se opunha à - ou complementava a - noção de sexo e pretendia referir-se aos comportamentos, atitudes ou traços de personalidade que a cultura inscrevia sobre o corpo sexuado. Nestas perspectivas, a ênfase na construção social de gênero não foi, necessariamente, acompanhada de problematizações acerca de uma "natureza" biológica universalizável do corpo e do sexo. Ou seja, em algumas dessas vertentes continua(va)-se operando com o pressuposto de que o social e a cultura agem sobre uma base biológica universal que os antecede (MEYER, 2005, p. 15).
\end{abstract}

É necessário pensar, então, que os sujeitos não são apenas homens ou mulheres, mas homens e mulheres de várias etnias, classes, religiões, gerações, etc. portanto, há diferentes mulheres e diferentes homens sendo que suas identidades se constroem ao longo da vida através de inúmeras práticas sociais. No cerne dessa representação, está a percepção de que o sujeito universal não passa deuma invenção. A morte do sujeito universal permite a emergência dos outros não como outros do mesmo (o outro do próprio sujeito universal), mas um outro sujeito a ele irredutível e de dignidade equivalente (IRYGARAY, 2002): o sujeito plural, heterogêneo e contingente.

No campo da História, esse movimento tem início da década de 60 do século XX:

[...] pois foi nesses anos que ocorreu o registro, na história, de grupos anteriormente "silenciosos" de-

Movimento, Porto Alegre, v.13, n. 02, p.171-196, maio/agosto de 2007. 
finidos por diferenças de raça, sexo, preferências sexuais [...] Na década de 60, muitas [...] questões foram bruscamente trazidas à tona, quando o político e o estético se fundiram na chamada contracultura [...] Os negros e as feministas, os etnicistas e os gays, as culturas nativa e do "terceiro mundo" não formam movimentos monolíticos, mas constituem diversidade de reações a uma situação de marginalidade e excentricidade percebida por todos (HUTCHEON, 1991, p. 89-90).

Esse olhar sobre o sujeito possibilitou que vários "outros" saíssem das zonas de sombras nos quais foram posicionados. Permitiu compreender, ainda que a História, mais do que revelar verdades, busca fissurar o passado, reivindicando:

[...] a poderosa força da imaginação para detectar o possível, o silenciado, os comportamentos e relações humanas que não obedecem aos estereótipos e padrões; aponta para um universo onde a fissura é a superfície, pois reconhece como construídos os paradigmas de "mentalidades hegemônicas" ou de "visões de mundo", compartilhadas por uma maioria (SWAIN, 2004).

Ao romperem com o pensamento binário, que coloca em oposição mulheres e homens, as historiadoras feministas pós-estruturalistas colocam em questão o pensamento iluminista da modernidade que, baseado em dicotomias hierarquizantes (racionalidade/ irracionalidade, corpo/mente, natureza/cultura, sujeito/objeto) relegou a mulher a um estatuto de inferioridade em relação ao homem.

Para Judith Butler:

No feminismo, parece haver uma necessidade política de falar enquanto mulher e pelas mulheres, e não vou contestar essa necessidade. [...] Eu diria que qualquer esforço para dar conteúdo universal ou específico à categoria mulheres, supondo-se que essa garantia de solidariedade é exigida de antemão, produzirá necessariamente facções e que a "identidade" como ponto de partida jamais se sustenta como base sólida de um movimento político

Movimento, Porto Alegre, v.13, n. 02, p.171-196, maio/agosto de 2007. 
feminista. As categorias de identidade nunca são meramente descritivas, mas sempre normativas e como tal, exclusivistas. Isso não quer dizer que o termo "mulheres" não deva ser usado, ou que devamos anunciar a morte da categoria. Ao contrário, se o feminismo pressupõe que "mulheres" designa um campo de diferenças indesignáveis, que não pode ser totalizado ou resumido por uma categoria de identidade descritiva, então o próprio termo se torna um lugar de permanente abertura e re-significação (BUTLER, 2003, p. 25-6).

\title{
2 MULHERES, HISTÓRIAS E ESPORTE: O GÊNERO COMO UMA CATEGORIAANALÍTICA
}

\begin{abstract}
Os homens - no masculino e no feminino, na infância, na juventude, na maturidade e na velhice, do nascimento até à morte - não vivem apenas no meio dos objectos e dos pensamentos de todos os dias, vivem com o seu corpo, por meio do seu corpo. Este objecto de estudo da anatomia, da fi siologia, da biologia, transformou-se também em objecto da história. As representações colectivas do corpo, esse suporte da saúde, da doença, do exercício físico, da sexualidade são diferentes, conforme as sociedades e as épocas. A história do corpo só assume todo o seu significado ao nível do quotidiano (LE GOFF, 1994, p. 8).
\end{abstract}

Tanto quanto as mulheres, o corpo também foi, por muito tempo, esquecido pela historiografia tradicional que era "de fato, desencarnada. Interessava-se pelos homens e, secundariamente, pelas mulheres. Mas quase sempre sem corpo. Como se a vida dos homens se situasse fora do tempo e do espaço, reclusa na imobilidade presumida da espécie" (LE GOFF e TRUONG, 2006, p. 9).

Foi com a crise paradigmática vivida pela historiografia nos anos de 1970, que o corpo começou a conquistar maior visibilidade como objeto de estudo. ${ }^{11}$ Foi, também, nesse momento que os estudos feministas apostaram no conceito de gênero como uma

11 Sobre esse tema, ler A história do corpo e a Nova História: uma autópsia, de Mary Del Priori (1994).

Movimento, Porto Alegre, v.13, n. 02, p.171-196, maio/agosto de 2007. 
possibilidade de rejeitar o determinismo biológico implícito em termos tais como sexo ou diferença sexual.

Como ferramenta analítica, o termo "gênero" possibilitou desconstruir a representação naturalizada de que homens e mulheres constroem-se masculinos e femininos pelas diferenças corporais e que essas diferenças justificam determinadas desigualdades, atribuem funções sociais, determinam papéis a serem desempenhados por um ou outro sexo (GOELLNER, 2001). Possibilitou, sobretudo, identificar que os corpos, as gestualidades, as representações de saúde, beleza, performance e sexualidade são construções históricas que, em diferentes tempos e culturas foram associadas aos homens e/ou as mulheres, produzindo, ainda, representações de masculinidades e feminilidades.

Considerando que os corpos não se traduzem em matéria universalmente edificada pelos desígnios da natureza, enfatizo a importância da utilização do "gênero" como uma categoria analítica visto que esse conceito é importante para perceber os processos pelos quais, no interior de redes de poder, ${ }^{12}$ a diferença biológica é tomada para explicar desigualdades sociais gestando, assim, formas de inclusão e exclusão de sujeitos e grupos.

Vários outros argumentos poderiam ser utilizados para demarcar a importância dos estudos de gênero no campo da Educação Física e do esporte, não apenas nas abordagens historiográficas. No entanto, um deles, por si só, já garante sua existência: o gênero nos constitui, inscreve-se na nossa carne. Isso significa perceber que "[...] os corpos carregam discursos como parte de seu próprio sangue" (BUTLER apud PRINS e MEIJER 2002, p.163). Eles, os discursos, se acomodam no corpo e os generificam.

Os corpos fazem-se femininos e masculinos na cultura e essas representações, apesar de serem sempre transitórias, marcam nossa pele, nossos gestos, nossos músculos, nossa sensibilidade e nossa movimentação. Melhor dizendo: as marcas culturais que contornam as representações que temos de masculino e feminino são históricas,

${ }^{12}$ Poder aqui é tomado a partir da teorização de Michel Foucault que o percebe como difuso, descentralizado e horizontal.

Movimento, Porto Alegre, v.13, n. 02, p.171-196, maio/agosto de 2007. 
mutantes e provisórias. Simbólica ou física, essa marcação pode ser indicada, por exemplo:

[...] por uma aliança de ouro, por um véu, pela colocação de piercing, por uma tatuagem, por uma musculação "trabalhada", pela implantação de uma prótese... o que importa é que ela terá, além de efeitos simbólicos, expressão social e material. Ela poderá permitir que o sujeito seja reconhecido como pertencendo a determinada identidade; que seja incluído em ou excluído de determinados espaços; que seja acolhido ou recusado por um grupo; que possa (ou não) usufruir direitos; que possa (ou não) realizar determinadas funções ou ocupar determinados postos; que tenha deveres ou privilégios; que seja, em síntese, aprovado, tolerado ou rejeitado (LOURO, 2004, p. 84).

No campo do esporte, essa marcação não se dá de forma deslocada de outras tantas presentes no cotidiano dos indivíduos e seus corpos. Os gestos, as musculaturas, as roupas, os acessórios, os suplementos alimentares carregam consigo significados que, na nossa sociedade e no nosso tempo, estão também associados ao feminino e ao masculino. Essas marcas produzem efeitos e, não raras vezes, são reclamadas para justificar a inserção, adesão e permanência de homens e mulheres em diferentes práticas corporais e esportivas.

Além disso, induzem a acreditar que estas características já nascem grudadas ao sexo biológico e que são elas que determinam, em grande parte, os traços de caráter, o comportamento, as funções sociais, os espaços de pertencimento e as possibilidades de movimentação para eles e para elas. Esse pensamento está associado ao que se denomina de determinismo biológico, perspectiva teórica que sustenta a idéia de que as "normas comportamentais compartilhadas bem como as diferenças sociais e econômicas existentes entre os grupos humanos - principalmente de raça, classe e sexo - derivam de distinções herdadas e inatas" (GOULD, 1999, p. 4).

Se é a conformação anatômica dos sujeitos aquilo que os define, dentro dessa perspectiva, nada mais "natural" que recomendar aos homens e mulheres diferentes possibilidades de movimentação. A eles a aventura, a potência, o desafio, a força; a elas, a aventura

Movimento, Porto Alegre, v.13, n. 02, p.171-196, maio/agosto de 2007. 
comedida, a potência controlada, a força mensurada, o desafio ameno. Para as mulheres, em grande medida, é incentivado viver o espetáculo esportivo desde que não deixe de lado, por exemplo, a graciosidade, a delicadeza e a beleza, atributos colados uma suposta "essência feminina". ${ }^{13}$ Argumentos como estes operam como mecanismos de exclusão e inclusão em diferentes modalidades esportivas, posicionam as mulheres, demarcam seus espaços de sociabilidade, pois insistem em afirmar que determinadas atividades não são apropriadas aos seus corpos vistos, grosso modo, como de natureza mais frágil que os corpos dos homens. Para Hult:

[...] a participação feminina no esporte sempre foi alvo de muitas controvérsias. Há algumas décadas, as mulheres eram interditadas de participar de qualquer atividade esportiva, sob diversas alegações, desde sua fragilidade física, passando pela sua condição materna, e até mesmo pelo fato da arena esportiva fortalecer o espírito do guerreiro masculino, sendo apontado como o único local no qual a supremacia masculina seria incontestável (HULT apud KNIJNIK e VASCONCELLOS, 2003, p. 51).

A lógica que sustenta afirmações desse porte é aquela que vê homens e mulheres como seres diferentes e em oposição, possuidores de corpos que são igualmente diferentes e se constituem, igualmente em oposição. ${ }^{14}$ Por entenderem que a oposição binária engessa, fixa e determina comportamentos excludentes entre os sexos, algumas teóricas da segunda onda do

${ }^{13}$ Gostaria de enfatizar que elegi falar de mulheres e de feminilidades. O que não significa
que esteja tomando os homens e as masculinidades como deslocadas desse sistema da
representação e produção de sentidos. A questão aqui é política. É de conferir visibilidade ao
feminino o que, de forma alguma, significa considerar os homens como "inimigos". É,
exatamente, essa forma binária de ver e entender o mundo que estou tentando desconstruir.
${ }^{14}$ O livro Inventando o Sexo, de Thomas Laqueur (2001) é fundamental para entender essa
diferenciação. Ao analisar sexo e gênero desde os gregos ao século XVIII, evidencia uma
mudança significativa na noção de corpo. Até o século XVIII, imperava o que denomina da
"noção unissexuada" ou de sexo único, segundo a qual o corpo feminino era identificado
igual, no entanto, menos desenvolvido que o masculino. A partir desse período, o corpo
feminino passa a ser visto diametralmente diferente do masculino. Segundo Nicholson, "esta
tendência de ver as diferenças físicas que separam homens e mulheres em termos cada vez
mais binários, aparecia também a nova tendência a ver as diferenças físicas como a cauda
própria da distinção masculino/feminino" (2000, p. 20).

Movimento, Porto Alegre, v.13, n. 02, p.171-196, maio/agosto de 2007. 
feminismo ${ }^{15}$ investiram na desconstrução desta representação. Segundo Joan Scott (1995), o binarismo impossibilita a percepção das pluralidades e das diversidades, pois ao colocar os dois termos em oposição, constrói igualdade de cada lado da oposição ocultando, assim, as múltiplas identificações existente entre os lados opostos. O binarismo e o pensamento dicotômico exacerbam a oposição. Com isso, "cada lado da oposição é apresentado e representado como um fenômeno unitário. Assume que tudo em cada categoria (mulher/homem) é a mesma coisa (é igual); portanto, se suprimem as diferenças dentro de cada categoria" (MARIANO, 2005, p. 487).

Contrapondo-se a essa visão binária, as feministas pós-críticas têm evidenciado que existem diferentes formas de viver a feminilidade e masculinidade e estas se constroem dentro de relações sociais, nunca separadamente, nem mesmo em oposição de uma em relação à outra. Constroem-se na relação entre si e na articulação destas com outras categorias tais como classe, etnia, religião, geração, entre outros, tendo no corpo uma materialização dessa construção. Rompe-se, aqui, com a percepção de que há uma base biológica natural dada (o corpo) sobre a qual são sobrepostas as influências sociais (o comportamento, atitudes, personalidade).

Ao analisar a inexistência de uma relação linear entre biologia e socialização, Linda Nicholson (2000) afirma que a diferença sexual representa a persistência de um ponto comum entre várias culturas. Nesta perspectiva, as diferenças entre as mulheres são pensadas numa coexistência mais do que numa interseção, o que pode representar um equívoco. Para Nicholson, não há aspectos comuns emanando da biologia. Nas suas palavras:

A população humana difere dentro de si mesma, não só em termos de expectativas sociais sobre como pensamos, sentimos e agimos; há, também diferenças nos modos como entendemos o corpo. Conseqüentemente, precisamos entender as variações sociais na distinção masculino/feminino como

\footnotetext{
${ }^{15}$ A denominada "segunda onda do feminismo" tem seu início no final da década de 1960 cujas preocupações além de estarem situadas no plano social e político voltam-se, também, para as construções teóricas. É nesse contexto que o gênero desponta como uma ferramenta analítica.

Novimento, Porto Alegre, v.13, n. 02, p.171-196, maio/agosto de 2007.
} 
relacionadas a diferenças que "vão até o fundo" aquelas diferenças ligadas não só aos fenômenos limitados que muitas vezes associamos ao "gênero" (isto é, a estereótipos culturais de personalidade e comportamento), mas também a formas culturalmente variadas de se entender o corpo. Essa compreensão não faz com que o corpo desapareça da teoria feminista. Com ela o corpo se torna, isso sim, uma variável, mais do que uma constante, não mais capaz de fundamentar noções relativas à distinção masculino/feminino através de grandes varreduras da história humana, mas sempre presente como elemento importante na forma como a distinção masculino/feminino permanece atuante em qualquer sociedade. (NICHOLSON, 2000, p. 8-9).

Ao refutar a assertiva de que a identidade sexual prevê um eu masculino ou feminino precisamente diferenciado e profundamente enraizado num corpo diferenciado sexualmente, Nicholson (2000) analisa que, embora muitas sociedades e culturas possuam distinções masculino/feminino e também as relacionem, de forma mais ou menos significativa ao corpo, as:

[...] diferenças sutis na forma como o próprio corpo é pensado podem ter algumas implicações fundamentais para o sentido do que é ser homem ou mulher e representar, conseqüentemente, diferenças importantes no grau e no modo como o sexismo opera. (NICOLSON, 2000, p. 30).

Pensar essa representação no campo da Educação Física e do esporte implica deixar de observar o corpo como um dado natural e universal sobre o qual se agregam valores, atitudes, comportamentos, gestualidades e performances. Pressupõe entender que, por mais que o corpo possa ser identificado como o local primeiro a designar diferenciações sociais é nele que reside os princípios de sua ruína. Nesse sentido, as justificações biológicas que fundamentam as recomendações diferenciadas para mulheres e homens no campo do esporte merecem, no mínimo, serem observadas com desconfiança.

Referindo-se ao contexto canadense e norte-americano do início do século XX, a historiadora Helen Lenskyj chama a atenção para algo

Movimento, Porto Alegre, v.13, n. 02, p.171-196, maio/agosto de 2007. 
importante de ser considerado na rede de significações que giram em torno da participação e permanência das mulheres no esporte.

A habilidade esportiva dificilmente se compatibilizava com a subordinação feminina tradicional da sociedade patriarcal; de fato, o esporte oferecia a possibilidade de tornar igualitárias as relações entre os sexos. O esporte, ao minimizar as diferenças socialmente construídas entre os sexos, revelava o caráter tênue das bases biológicas de tais diferenças; portanto, constituía uma ameaça séria ao mito da fragilidade feminina (LENSKYJ apud ADELMAN, 2004, p. 448).

Noutras palavras: os argumentos biológicos que historicamente têm servido para naturalizar as diferenças sociais entre sujeitos perdem força e legitimidade diante da percepção de que se traduzem em construções discursivas atreladas a redes de significação e de poder. O poder, por exemplo, de indicar as modalidades que homens e mulheres podem/devem praticar, de classificar níveis de performance possíveis de serem desenvolvidos, de inferir as habilidades e capacidades físicas de cada um, de nomear aquelas/aqueles que correspondem a essas expectativas ou, ao contrário, quem delas escapa. ${ }^{16}$

O corpo não está fora da cultura e da história. Como objeto de conhecimento é uma categoria construída por um discurso particular que, ao enfatizar as diferenciações biológicas, o trata como dado e natural. O discurso biológico que legitima a diferenciação entre homens e mulheres no esporte não passa, portanto, de uma construção discursiva. Essa afirmação de modo algum nega a existência de diferenças biológicas entre os sexos, mas propõe um deslocamento do foco central da análise: mais do que buscar explicações que possam medir, comparar ou explicar fisiologicamente as diferenças entre as performances do homem e da mulher no esporte,

${ }^{16}$ Desnaturalizar essas construções tem sido um investimento identificado, tanto em alguns estudos historiográficos como em estudos que utilizam o conceito de gênero para analisar a participação das mulheres no esporte brasileiro. Dentre eles, cito Mourão (1998), Oliveira (2002), Devide (2002), Knjinick (2003), Romero (2005), entre outros.

Movimento, Porto Alegre, v.13, n. 02, p.171-196, maio/agosto de 2007. 
deveríamos nos indagar porque essas diferenças, e não outras quaisquer, são tomadas como as mais importantes para demarcar tal distinção (WILLIS, 1994 apud DEVIDE, 2005). Ao invés de afirmar, por exemplo, que mulheres bóiam mais facilmente que homens, ${ }^{17}$ deveríamos averiguar os motivos pelos quais a anatomia sexual tem sido território privilegiado para questionar a presença de mulheres em esportes como o futebol, o rugby, as lutas ou o fisioculturismo.

De outro modo: não é o corpo "em si" que define a modalidade esportiva mais adequada para uma mulher nem mesmo se ela tem ou não capacidade para dirigir uma federação esportiva ou para treinar uma equipe de alto rendimento. É a discursividade construída sobre a funcionalidade do corpo e sua correlata associação aos processos de socialização que provoca e constrói tais demarcações. Somente quando dissociarmos a biologia da socialização é que seremos capazes de identificar que os corpos, os comportamentos, as masculinidade e as feminilidades são plurais. ${ }^{18}$ Poderemos, então, aceitar que o esporte é um local de produção de corpos generificados, não porque são generificados em sua essência, mas porque são assim construídos no interior das práticas, saberes e discursos que o integram e que estão no seu entorno.

É inquestionável a visibilidade que o esporte, nas suas mais diferentes dimensões, tem na cultura contemporânea. Tornou-se um território de exposição de corpos femininos e masculinos que, ao exibirem-se e serem exibidos, educam outros corpos. Educam a consumir produtos e serviços, idéias e representações (de saúde, sensualidade, beleza, sucesso, etc.), a desfilar marcas, a padronizar gestos, a comercializarem-se, a fabricar imagens heróicas, a expressar emoções, a superar limites, a criar necessidades e também a vender

\footnotetext{
${ }_{17}$ Referência à reportagem publicada no jornal Zero Hora que, depois de indagar quem flutua melhor, faz a seguinte consideração: "Homens e mulheres têm uma densidade inferior à da água, mas a das mulheres é um pouco menor $\left(0,962 \mathrm{~kg} / \mathrm{m}^{3}\right.$ delas contra $0,978 \mathrm{~kg} / \mathrm{m}^{3}$ deles $)$. Isso se deve, entre outros fatores, a uma constituição corporal que inclui ossos menos densos, bacia maior que a cintura e mais quantidade de tecido adiposo (gordura), todos relacionados à gestação. Portanto, as mulheres flutuam melhor que os homens, que precisam empregar força muscular para obter uma melhor sustentação na água" (LOPES e SANTOS, 2004, p. 32).

${ }^{18}$ Sobre a relação biologia e cultura na atribuição de sentidos ao corpo e ao gênero ler Donna Haraway (1992) e Luis Henrique dos Santos (2004).
}

Movimento, Porto Alegre, v.13, n. 02, p.171-196, maio/agosto de 2007. 
o próprio corpo como um dos produtos de uma sociedade que valoriza o espetáculo, o consumo, a estética, a juventude e a produtividade. Educam, também, masculinidades e feminilidades.

Questões como estas só puderam emergir, no campo da Educação Física e do esporte, com o surgimento de estudos que analisaram estes fenômenos a partir da categoria gênero (articulados ou não à perspectiva historiográfica). ${ }^{19}$ Nesse sentido, é inegável a contribuição da teorização feminista cuja pluralidade de análise não a torna menos importante no campo acadêmico. Ao contrário, sua presença no campo da ciência tem demonstrado que o conhecimento não é algo estático, universal ou mesmo consensual. O conhecimento é interessado e, como um campo de disputa, está constantemente atravessado por relações de poder.

Por essa razão, reafirmo a importância das epistemologias feministas e dos estudos de gênero para compreender os processos históricos e contemporâneos através dos quais se deu a inserção, permanência e ampliação da participação das mulheres no campo das práticas corporais e esportivas. Mais especificamente, aquelas abordagens relacionadas ao feminismo pós-crítico que, ao romperem com a categoria universal "mulher", têm visibilizado as diferenciações e pluralidades presentes nos modos das mulheres existirem e de viverem suas feminilidades.

Ao eliminarem do horizonte analítico o determinismo biológico e os binarismos, estes estudos favorecem a aceitação da profusão de feminilidades e de masculinidades, da permeabilidade entre as fronteiras corporais e a não fixidez das identidades. Permitem, ainda, compreender que o esporte não é um campo "naturalmente" masculino, nem mesmo aquelas modalidades que exigem maior força física e vigor: como qualquer outra instância social, o esporte é um espaço de generificação, não porque reflete as desigualdades e diferenciações da sociedade em geral mas, fundamentalmente, porque as produz e reproduz.

\footnotetext{
${ }^{19}$ Uma análise sobre a produção acadêmica dos estudos de gênero na Educação Física brasileira pode ser encontrada no livro Educação Física e Gênero: olhares em cena, de Agripino Luz Júnior, publicado em 2003.

Movimento, Porto Alegre, v.13, n. 02, p.171-196, maio/agosto de 2007.
} 
Reclamar às mulheres o direito de reivindicar o esporte como um espaço de exercício de liberdades que também é seu, mais do que um desafio acadêmico é, sim, uma necessidade política. Afinal, como afirma Susan Bordo:

Numa cultura que é de facto construída pela dualidade sexual, não se pode ser simplesmente "humano". Isso é tão impossível quanto é impossível ser-se simplesmente "gente" numa cultura racista [...] A nossa linguagem, história intelectual e formas sociais são sexuadas. Não podemos fugir a este facto nem às conseqüências que ele tem nas nossas vidas. Algumas destas conseqüências podem não ser intencionais, podem até ser ferozmente combatidas; o nosso maior desejo pode ser "transcender as dualidades da diferença sexual"; não ter o nosso comportamento categorizado em termos de "masculino" e "feminino". Porém, quer nos agrade ou não, na cultura presente as nossas actividades são codificadas como "masculinas" ou "femininas" e funcionarão como tal no sistema prevalecente das relações de poder entre os sexos (BORDO apud MACEDO e AMARAL, 2005).

Movimento, Porto Alegre, v.13, n. 02, p.171-196, maio/agosto de 2007. 


\begin{abstract}
Feminism, Women and Sport: epistemological issues for historiographic work

Abstract: This text analyzes the contribution of feminist epistemologies and gender studies for historiographic work on women in sport. With these purposes in mind, we evaluate the emergence of a field that has been denominated "Women's History", as well as the use of the category "gender" as an analytical tool that makes it possible to understand the historical processes through which women's entrance, participation and growing presence in the field of sporting and bodily practices occur. Furthermore, we give salience to the theorizations of post-critical feminism, which in breaking with the universal category of "woman" has made the differences and pluralism that characterize the way women live and experience their femininities visible. Keywords: Feminism. Women. Sports. History.
\end{abstract}

Feminismos, mujeres y deportes: cuestiones epistemológicas sobre el hacer historiográfico Resumen: Este texto analiza la contribución de las epistemologías femeninas y de los estudios de género para las investigaciones historiográficas sobre mujeres y deportes. Para tanto, analiza el emergente campo denominado de "Historia de las mujeres" así como la utilización de la categoría "género"como herramienta analítica que posibilita comprender los procesos históricos a través de los cuales se dio la inserción, la permanencia y ampliación de la participación de mujeres en el campo de las prácticas corporales y deportistas. Enfatiza, aún, las teorías del feminismo pos-crítico en vista de que, al romper con la categoría universal "mujer" tiene visualizado las diferencias y las pluralidades presentes en la manera de las mujeres existieren y de vivieren su feminidad.

Palabras claves: Feminismo. Mujeres. Deportes. Historia.

\title{
REFERÊNCIAS
}

ADELMAN, Miriam. O desafio das amazonas: a construção da identidade de mulheres como atletas e amazonas do hipismo clássico (salto) brasileiro. In: SIMÕES, Antônio Carlos; KNIJNICK, Jorge D. (orgs.). O mundo psicossocial da mulher no esporte: comportamento, gênero, desempenho. São Paulo: Aleph, 2004. p. 277-303.

Movimento, Porto Alegre, v.13, n. 02, p.171-196, maio/agosto de 2007. 
BUTLER, Judith. Problemas de gênero. Rio de Janeiro: Civilização Brasileira, 2003.

CORAZZA, S. M. Labirintos da pesquisa, diante dos ferrolhos. In: COSTA, Mariza V. (org.) Caminhos Investigativos: novos olhares na pesquisa em educação. Rio de Janeiro: DP\&A, 2002. p. 105-131.

DE CERTEAU, Michel. A escrita da História. Rio de Janeiro: Forense Universitária, 1982.

DEL PRIORI, Mary Lucy. A história do corpo e a Nova História: uma autópsia. Revista da USP, São Paulo, n. 23, p.11-20, jan./abr., 1994.

DEL PRIORI, Mary L.; BASSANEZZI, Carla. História das Mulheres no Brasil. Rio de Janeiro: Contextos, 1997.

DEVIDE, Fabiano. História das mulheres na natação brasileira do século XX. 2002, 421f. Tese (Doutorado). Programa de Pós-Graduação em Educação Física. Curso de Educação Física, Universidade Gama Filho, Rio de Janeiro, 2002.

Gênero e mulheres no esporte: história das mulheres nos Jogos Olímpicos Modernos. Ijuí: Editora UNIJUÍ, 2005.

FOUCAULT, Michel. Microfísica do Poder. Rio de Janeiro: Graal, 1992.

GOELLNER, S. V. Gênero, Educação Física e esportes. In: VOTRE, Sebastião (org). Imaginário \& representações sociais em educação física, esporte e lazer. Rio de Janeiro: Gama Filho, 2001, p. 215-227.

Bela, maternal e feminina: imagens da mulher na Revista Educação Physica. ljuí: Editora UNIJUÍ, 2003.

Mulheres e futebol no Brasil: entre sombras e visibilidades. Revista Brasileira de Educação Física e Esporte, São Paulo, v. 19, n. 2, p. 143-152, abr./jun., 2005.

GONÇALVES. Andréa L. História \& Gênero. Belo Horizonte: Autêntica, 2006.

GOULD, Stephen J. A falsa medida do homem. São Paulo: Martins Fontes, 1999.

HARAWAY, Donna. The promisses of monsters: a regenerative politics for inappropriate/d others. In: GROSSBER, Laurence et al. (org.). Cultural Studies. New York: Routledge, 1992. p. 45-62.

HUTCHEON, Linda. Poética do Pós-Modernismo. Rio de Janeiro: Imago, 1991.

Movimento, Porto Alegre, v.13, n. 02, p.171-196, maio/agosto de 2007. 
KING, Samantha J; McDONALD, Mary G. (Post)Identity and Sport cultures: Introduction and Overview. Sociology of Sport Journal, Champaign, v. 24, n. 1, p. 1-19, 2007.

KNIJNIK, Jorge Dorfman. A mulher brasileira e o esporte: seu corpo, sua história. São Paulo: Mackenzie, 2003.

KNIJNIK, Jorge D.; VASCONCELLOS, Esdras G. Sem impedimento: o coração aberto das mulheres que calçam chuteiras no Brasil. In: COZAC, João Ricardo (ed.). Com a cabeça na ponta da chuteira: ensaios sobre a psicologia do esporte. São Paulo, Annablume/Ceppe, 2003. p. 123-142.

LAQUEUR, Thomas. Inventando sexo: corpo e gênero dos gregos a Freud. Rio de Janeiro: Relume Dumará, 2001.

LE GOFF, Jacques. A História do Quotidiano. In: ARIÈS, P., DUBY, G. ; LE GOFF, Jacques. História e Nova História. Lisboa: Teorema, 1994.

LE GOFF, Jacques; TROUG, Nicolas. Uma história do corpo na Idade Média. Rio de Janeiro: Civilização Brasileira, 2006.

LOPES, Cláudio A. e SANTOS, Márcia R. As mulheres bóiam mais facilmente? Zero Hora, Porto Alegre, p. 32, 20 de ago. 2004.

LOURO, Guacira L. Gênero, sexualidade e educação: uma perspectiva pósestruturalista. Petrópolis: Vozes, 1997.

Um corpo estranho: ensaios sobre sexualidade e teoria queer. Belo Horizonte: Autêntica, 2004.

LUZ JÚNIOR, Agripino. A Educação Física e Gênero: olhares em cena. São Luis: Imprensa Universitária/UFMA/CORSUP, 2003.

MACEDO, Ana; AMARAL, Ana Luisa. Dicionário da crítica feminista. Porto: Afrontamento, 2005.

MARIANO, Silvana A. O sujeito do feminismo e o pós-estruturalismo. Revista Estudos Feministas, Florianópolis, v.13, n. 3, p. 483-505, set./dez., 2005.

MEYER, D. E. Cultura teuto-brasileiro-evangélica no Rio Grande do Sul: articulando gênero com raça, classe, nação e religião. Educação \& Realidade, Porto Alegre, v. 25, n. 1, p. 135-62, jan./jul., 2000.

Gênero e educação: teoria e política. In: LOURO, Guacira; NECKEL, Jane; GOELLNER, Silvana V. Corpo, gênero e sexualidade: um debate contemporâneo em educação. 2. ed. Petrópolis: Vozes, 2005.

Movimento, Porto Alegre, v.13, n. 02, p.171-196, maio/agosto de 2007. 
MOURÃO, Ludmila. A representação social da mulher na atividade físicodesportiva: da segregação à democratização, 1998. 313 f. Tese (Doutorado). Programa de Pós-Graduação em Educação Física. Curso de Educação Física, Universidade Gama Filho, Rio de Janeiro, 1998.

NICHOLSON, Linda. Interpretando Gênero. Revista Estudos Feministas, Florianópolis, v. 8, n. 2, p. 9-42, jul./dez., 2000.

OLIVEIRA, Gabriela Aragão. Representações sociais de mulheres técnicas sobre o comando de equipes esportivas de alto nível. Rio de Janeiro, 2002. 135f. Dissertação (Mestrado). Programa de Pós-Graduação em Educação Física, Curso de Educação Física, Universidade Gama Filho, Rio de Janeiro, 2002.

PERROT, Michele. Os excluídos da história: operários, mulheres e prisioneiros. Rio de Janeiro: Paz e Terra., 1988.

PERROT, Michele; DUBY. História das Mulheres no Ocidente. Porto: Afrontamento, São Paulo: EBRADIL, 1991.

PESAVENTO, Sandra J. História \& História Cultural. Belo Horizonte: Autêntica, 2003.

PFISTER, Gertrud; HARTMANN-TEWS, Ilse. Women and sport in comparative and international perspective: issues, aims and theoretival approaches. In: HARTMANN-TEWS, Ilse; PFISTER, Gertrud. (eds.). Sport and Women: social issues in international perspective. London: Houtledge, 2003. p 21-34.

PRINS, Baukje; MEIJER, Irene C. Como os corpos se tornam matéria: entrevista com Judith Butler. Revista Estudos Feministas. Florianópolis, v. 10, n. 1, p. 155-167, jan./jul., 2002.

ROMERO, Elaine. E, agora, vão fotografar o quê? As mulheres no esporte de alto rendimento e a imprensa esportiva. Labrys: estudos feministas, v. 8, ago/ dez 2005. Disponível em <http://www.unb.br/ih/his/gefem/labrys8/perspectivas/ elaine.htm> Acesso em 15 abr. 2007.

SANTOS, Luis Henrique dos. Biologia tem uma história que não é natural. In: COSTA, Marisa Vorraber. (org.) Estudos Culturais em educação: mídia, arquitetura, brinquedo, biologia, literatura, cinema... Porto Alegre: Editora da UFRGS, 2004. p. 229-256.

SCOTT, Joan. História das Mulheres. In: BURKE, Peter (org.) A escrita da história: novas perspectivas. São Paulo: Editora da Universidade Estadual de São Paulo, 1992. p. 63-96.

Gênero: uma categoria útil de análise histórica. Educação \& Realidade, Porto Alegre, v.20, n.2, p. 71-99, jul./dez., 1995.

Movimento, Porto Alegre, v.13, n. 02, p.171-196, maio/agosto de 2007. 
SILVA, Paula; GOMES, Paula B; GRAÇA, Amândio; QUEIRÓS, Paula. Acerca do debate metodológico na investigação feminista. Revista Portuguesa de Ciências do Desporto. Porto, v.5, n. 3, p. 358-370, set./dez., 2005.

SILVA, Thomaz Tadeu da. Teoria cultural e educação: um vocabulário crítico. Belo Horizonte: Autêntica, 2000.

STOLKE, V. La mujer es puro cuento: la cultura del género. Revista Estudos Feministas, Florianópolis, v. 12, n. 2, p.77-105, 2004.

SWAIN, T. N. Intertextualidade: perspectivas feministas e foucaultianas. Labrys: estudos feministas, v. 4, jan/jul 2004. Disponível em <http://www.unb.br/ih/ his/gefem/labrys5/textos/eubr.htm>. Acesso em:15 abr. 2007.

YRIGARAY, Lucy. A questão do Outro. Labrys: estudos feministas, v.1-2, jul/ dez 2002. Disponível em <http://www.unb.br/ih/his/gefem/labrys5/textos/ eubr.htm>. Acesso em 23 mar. 2007.

Movimento, Porto Alegre, v.13, n. 02, p.171-196, maio/agosto de 2007. 